\title{
Possibilities for De-carbonizing the Heating and Cooling Sector in the Island of Crete, Greece
}

\author{
John Vourdoubas
}

\section{ABSTRACT}

Clean energy transition in islands is important and urgent in the current era of climate change. The possibility of de-carbonizing the heating and cooling sector in the island of Crete, Greece has been investigated. Fossil fuels are used in Crete in electricity generation, in heat and cooling production as well as in transportation. The use of various renewable and non-renewable fuels as well as the technologies used in heat and cooling generation has been examined together with the annual changes in fossil fuels consumption during the last years. Various renewable energies like solar energy, biomass and low enthalpy geothermal energy combined with renewable electricity could cover all the heating and cooling requirements in Crete totally eliminating the use of fossil fuels. Their technologies are mature, reliable, and cost efficient. Renewable and low cost electricity can be easily generated by the abundant solar and wind energy resources in Crete powering electric systems generating heat and cooling. Current work indicates that the heating and cooling sector in Crete can be de-carbonized. This would result in the mitigation of climate change complying with the European goal for carbon neutrality in Europe by 2050.

Keywords: heat, cooling, renewable energies, Crete, de-carbonization, carbon emissions.

Published Online: June 13, 2021

ISSN: 2684-446X

DOI : $10.24018 /$ ejgeo.2021.2.3.143

John Vourdoubas*

Consultant Engineer, 107B, El. Venizelou str., 73132, Chania, Crete, Greece. (e-mail: vourhome@otenet.gr)

*Corresponding Author

\section{INTRODUCTION}

De-carbonization of the energy sector in islands is important for climate change mitigation. Many studies have been realized and efforts have been made to decouple energy generation from fossil fuels consumption aiming to achieve carbon neutral societies by the middle of the $21^{\text {st }}$ century. De-carbonization of the heat and cooling sector in the island of Crete, Greece has not been studied so far. Heat and cooling are currently generated in Crete using fossil fuels, electricity and locally available renewable energies including solar energy and solid biomass. Zeroing $\mathrm{CO}_{2}$ emissions in heat and cooling generation requires the replacement of fossil fuels used so far with renewable energies and energy systems using renewable electricity. De-carbonization of the heating and cooling sector in Crete can be achieved with the combined use of energy saving systems, increase of energy efficiency in existing systems, electrification of the heating sector and higher use of various locally available renewable energies (REs). Eliminating carbon emissions in heat and cooling generation combined with their elimination in electricity generation as well as in transportation would result in zeroing the carbon footprint due to energy use in Crete complying with the European target for carbon neutral Europe by 2050 .

\section{LITERATURE SURVEY}

A. Heat and Cooling Generation with Electricity,
Renewable Energies and Low Carbon Energy
Technologies

The use of electric heaters for thermal storage has been studied [1]. The authors stated that thermal storage tanks can decouple energy generation and demand enhancing the use of solar and wind energy. They also mentioned that when electricity demand is low surplus wind and solar electricity can be stored in thermal storage units. The stored thermal energy can be used when heat is needed avoiding the use of fossil fuels. The European residential wood pellet trade has been reviewed [2]. The authors stated that the European market for wood pellets used in small scale heating systems has been expanded rapidly. They also mentioned that wood pellet's prices are higher in the winter than in the rest of the year while the highest prices are found in Italy and the lowest in Austria. The performance of solar thermal systems used in hotels particularly in Mediterranean region has been investigated [3]. The authors compared a conventional system using heating oil in a Greek hotel with an alternative system using solar thermal collectors combined with an air to water heat pump. They concluded that the combined system significantly reduced the energy consumption while its $\mathrm{CO}_{2}$ emissions were also less. The Greek solar thermal market has been reviewed [4]. The author stated that the 
Greek solar thermal market has grown between 2016 and 2018 while the installed solar thermal collector area per capita is very high, compared with other EU countries, at $0.437 \mathrm{~m}^{2}$. He also mentioned that the Greek solar thermal industry employs 1,820 people contributing in the National GDP at 316 mil $€$ while $33 \%$ of the households are based on solar thermal systems for domestic hot water (DHW) production. A report regarding district heating in buildings has been published [5]. Comparison of district heating with other heating systems like heat pumps, wood pellets and solar energy has been made. District heating is characterized with steady prices, moderate investment costs, low maintenance costs, low environmental impacts, and high reliability. The design of a small co-generation of heat and power (CHP) system for three school buildings in the town of Matera, Italy has been studied [6]. The authors stated that when the CHP system was designed to cover the electricity demand of the buildings its power was at $90 \mathrm{KW}_{\mathrm{el}}$ while the payback period of the investment was estimated at 3-4 years. When the system was designed to cover both the electricity and heat requirements various energy saving interventions in the buildings were needed and the payback period in that case was estimated at 6-7 years. The use of CHP technology in apartment buildings in Mexico has been studied [7]. The authors applying simulation techniques investigated the use of gas turbines providing electricity, DHW, air-conditioning and water heating in a swimming pool. The electric power of the system was estimated at 1.1 MW, its total efficiency at $84.4 \%$ while it was profitable when the natural gas price was below $\$ 0.014 / \mathrm{KWh}$. The growth of solar thermal systems in EU and in Greece has been studied [8]. The author stated that the operating solar thermal capacity per 1,000 inhabitants in EU was at 30.7 $\mathrm{KW}_{\text {th }}$, in Cyprus at $562 \mathrm{KW}_{\text {th }}$, in Austria at $244 \mathrm{KW}_{\text {th }}$ while in Greece which ranks in the third position among EU countries was at $225 \mathrm{KW}_{\text {th. }}$. The majority of solar thermal applications in Greece are thermosiphonic systems with flat plate collectors while only few systems have vacuum tubes. The most of these systems have been installed in residential buildings, less in hotels and fewer in industries. The use of solar thermal cooling technologies in Greece has been reviewed [9]. The authors implemented an economic evaluation of two types of solar thermal cooling systems including absorption and adsorption systems. They mentioned that due to their high investment cost these cooling systems are marginally competitive with conventional systems at present energy prices. A report on solar cooling has been published by International Energy Agency [10]. It is stated that solar cooling can be achieved with different systems comprising a) Solar photovoltaic (Solar-PV) systems with vapor compression cooling machines, and b) solar thermal systems combined with thermally driven sorption chillers. The report mentioned that more than 1,500 solar cooling systems based on solar thermal collectors have been installed during the last years while the increased use of solar energy significantly decreases the pressure on the electricity grid. The operation of a solar absorption cooling and heating unit has been investigated [11]. The system included a sorption chiller with cooling capacity at $10 \mathrm{KW}$ and evacuated tubes with total surface at $40 \mathrm{~m}^{2}$. The maximum coefficient of performance (COP) achieved during a summer week in Athens, Greece was estimated at around 0.575 with driving temperature at $75{ }^{\circ} \mathrm{C}$. A report on solar heating and cooling for residential applications has been published [12]. The report stated that solar thermal technology is mature for residential applications while in some countries $80-90 \%$ of their homes have installed solar thermal systems for DHW production. It is also mentioned that by 2013 more than 1,000 solar thermal cooling systems were installed while $80 \%$ of them were in EU countries. The biomass potential of agricultural wastes for energy generation in Greece has been evaluated [13]. The authors stated that Crete produces $1,959,124 \mathrm{tn} /$ year agricultural residues while the most of them are based on olive pits and olive tree pruning. The biomass energy potential in the island of Samothrace, Greece has been evaluated [14]. The authors estimated that the annual energy availability from firewood burning was at 3,822 MWh while the total annual bio-energy availability in Samothrace was at 6,636 MWh. The generated heat could cover approximately half of the annual heating needs of the 2,859 inhabitants in the island. The direct use of geothermal energy worldwide has been studied [15]. The authors stated that the installed geothermal heat power has been increased by almost $45 \%$ over the last five years while over $50 \%$ of the total thermal energy produced was from ground-source heat pumps (GSHP). The recent trends in solar thermal cooling technology using sorption systems have been reviewed [16]. The authors stated that solar thermal cooling is the best alternative solution to conventional cooling using fossil fuels while cooling is needed when the solar irradiance is high. They also mentioned that absorption cooling systems achieve $\max \mathrm{COP}$ at 0.8 while the conventional cooling systems have COPs at 3 or even higher. Adsorption cooling systems have lower COP up to 0.45 . The future prospects of geothermal energy in space conditioning in buildings focused on India have been studied [17]. The authors stated that air-conditioning in a building has a share at around $40-50 \%$ in the total energy consumption in the country while the electricity demand for air-conditioning will be greatly increased in the future. They also mentioned that GSHPs have a huge potential in space air-conditioning and in DHW production over the conventional energy systems. The use of electric boilers and heat pumps in demand side management has been examined [18]. The authors stated that the storage capacity of electric boilers allows their operation with freedom in order to respond to power systems fluctuations.

\section{B. Energy Transition in Islands}

The de-carbonization of the heating sector using REs has been reported [19]. The report mentioned that the heating sector is responsible for around $50 \%$ of our energy consumption while solar thermal energy, biomass as well as geothermal and air source heat pumps can be used for DHW production and space heating in residential buildings. It is also stated that REs can cover all the heat requirements in households, agriculture, industry as well as in the tertiary sector while only when high temperatures above $400{ }^{\circ} \mathrm{C}$ are required in industry it is difficult to be covered by REs. The use of electricity generated by REs for heat and cooling production has been reported [20]. It is mentioned that $51 \%$ 
of the total energy demand in Europe is consumed for heating and cooling. The report mentioned that renewable electricity can be used with electric boilers for water heating providing space heating and DHW as well as for powering heat pumps generating heat, cooling and DHW. A study regarding the use of REs for heating in Europe has been published [21]. With reference the RES-H EU directive the report mentioned that heat can be produced from biomass, active solar thermal systems, and geothermal energy via heat pumps. A preliminary evaluation regarding the final use of energy in Crete has been made [22]. Energy consumption has been categorized in four sectors comprising a) electricity, b) heat and cooling, c) transportation inside the island and d) transportation from and to the island. The share of electricity in the final energy mix has been estimated at $20 \%$ of heat and cooling at $6 \%$, of transportation inside the island at $27 \%$ while the transportation from and to Crete at $47 \%$. A guide regarding the development of a clean energy transition agenda for islands has been published [23]. The guide mentioned that the cooperation and the involvement of all stakeholders is necessary for developing and implementing a successful clean energy transition plan. According to the quadruple helix model stakeholders from Academia, industry, public authorities, and the civil society should participate. A catalogue of good practices regarding clean energy transition in EU islands has been published [24]. Various small and larger EU islands, which are in the process of clean energy transition, are mentioned. The current status of the fuels used and the plans of REs deployment for reducing carbon emissions are stated. The possibility of financing the transition to low carbon energy in Europe has been examined [25]. The authors stated that the current financial sources and mechanisms can provide two to six times the required capital. Additionally, they mentioned, household investments are needed to finance small scale and low risk REs projects. Four different cases of transition management to sustainable development in the Netherlands have been investigated [26]. The authors stated that transition management offers a new approach to dealing with complex societal problems. They also mentioned that the learning by doing approach of transition management presents a useful strategy for guiding social innovation processes. The availability of biomass resources for energy generation in Crete has been studied [27]. The author stated that the main biomass resources used for heat generation in the island are olive kernel wood and olive tree wood. Additionally, he mentioned, small quantities of citrus cuttings and forest residues are also used for heat generation in Crete. Estimation of the fossil fuels used in Crete for heating including diesel oil, fuel oil and LPG has been published [28]. The transitioning of island's energy systems focusing on the islands of Samso, Orkney and Madeira have been examined [29]. The authors presented different scenarios regarding the introduction of new technologies in electricity generation as well as in other sectors for achieving $100 \%$ RE systems. They stated that local conditions, sector integration, smart grid solutions and balancing technologies have an important role in reaching $100 \%$ RE integration in the islands. The energy transition in Korcula island, Croatia has been studied [30]. The authors used computer simulation to evaluate the size of renewable energy systems for achieving a $100 \%$ renewable energy island. Their estimations were based on the assumption that only solar and wind energy were used while the electricity import and export in the island via electric transmission cables was balanced. The use of REs for energy generation in rural areas in Crete has been studied [31]. The author mentioned that solar energy is used for DHW production, solid biomass for heat production and heat pumps for heat and cooling generation. He also stated that the thermal power of the solar thermal systems installed in Crete for DHW production was at $186.4 \mathrm{MW}_{\text {th }}$. Existing studies indicate that REs and low carbon energy technologies can be used for heat and cooling generation as well as electric systems powered by renewable electricity. It is also indicated that clean energy transition in islands, regarding heat and cooling generation, can be achieved with various ways combining various sustainable energy systems and technologies.

Aims of the current research are:

a) The estimation of fossil fuels used for heat and cooling generation in Crete as well as the resulting carbon emissions,

b) The estimation of renewable energies that are currently used for heat and cooling generation in Crete, and

c) To examine the required renewable energy systems that could cover all the heat and cooling demand in the island replacing all the fossil fuels used.

After the literature survey the fuel's consumption and the energy technologies used in heat and cooling generation in Crete are mentioned. They are followed by the presentation of various renewable energy technologies and electric systems used in the heating and cooling sector in the island. After that the carbon emissions due to fossil fuels use are estimated and the possibility of de-carbonizing the heating and cooling sector in Crete is analyzed. In the last part of the text the discussion of the findings and the conclusions drawn are presented.

\section{USE OF FOSSIL FUELS FOR HEAT AND COOLING GENERATION IN CRETE}

Various fuels and technologies are currently used for heat and cooling generation in Crete presented in Table I.

TABLE I: FuELS AND TECHNOLOGIES USED FOR HEAT AND COOLING GENERATION IN CRETE

\begin{tabular}{ccc}
\hline Energy source & System/technology & Generated energy \\
\hline $\begin{array}{c}\text { Electricity and } \\
\text { ambient heat }\end{array}$ & Heat pumps & Heat and cooling \\
Electricity & Air-condition & Cooling \\
Electricity & Electric heaters and & Heat \\
boilers & Solar thermal collectors & Heat \\
Biomass & Burning & Heat \\
Diesel oil & Burning & Heat \\
Fuel oil & Burning & Heat \\
LPG & Burning & Heat \\
\hline
\end{tabular}

Source: Own estimations.

The global economic crisis in 2007-2008 had a strong impact in the Greek economy, reducing the National GDP and in the income of the Greek households. The Greek GDP is still around $30 \%$ lower than the pre-crisis levels. Due to the economic crisis the consumption of fossil fuels in the 
heating sector has been decreased while and the use of electricity and renewable energies has been increased. The fossil fuels consumption in the heating sector in Crete during 2006-2019 is presented in Table II. The present annual consumption of heating oil is approximately at one third (1/3) of the corresponding pre-crisis annual consumption in the island.

TABLE II: FossiL FuELS CONSUMPTION IN THE HEATING SECTOR IN CRETE (2006-2019)

\begin{tabular}{|c|c|c|c|}
\hline Year & Heating oil (tn) & Fuel oil (tn) & LPG (tn) \\
\hline 2019 & 40,294 & 6,683 & 26,425 \\
\hline 2018 & 29,881 & 6,180 & 25,387 \\
\hline 2017 & 42,019 & 6,330 & 24,570 \\
\hline 2016 & 39,301 & 6,204 & 23,618 \\
\hline 2015 & 47,782 & 6,458 & 22,733 \\
\hline 2014 & 26,982 & 5,728 & 20,686 \\
\hline 2013 & 25,123 & 5,661 & 19,745 \\
\hline 2012 & 69,493 & 5,192 & 18,151 \\
\hline 2011 & 99,814 & 6,694 & - \\
\hline 2010 & 86,895 & 7,884 & - \\
\hline 2009 & 110,785 & 9,501 & - \\
\hline 2008 & 110,552 & 10,197 & - \\
\hline 2007 & 127,008 & 10,119 & - \\
\hline 2006 & 136,554 & 11,366 & - \\
\hline
\end{tabular}

Part of the electricity used for heat and cooling generation in Crete is produced by renewable energies, mainly from solar and wind energy. The share of REs in electricity generation in Crete is estimated at around $22 \%$. Renewable energies used for space heating and DHW production in Crete include solar energy and biomass. Additionally, low enthalpy geothermal energy is used for heat and cooling generation with heat pumps powered by electricity. They are used in residential and commercial buildings, in agriculture and in industry. Natural gas infrastructure does not exist in Crete and this fuel is not currently used for energy generation in the island. The fossil fuels and the renewable energies used for heat generation in Crete as well as their $\mathrm{CO}_{2}$ emissions are presented in Table III.

TABLE III: FossIL FuELS AND RENEWABLE ENERGIES USED FOR HEAT GENERATION IN CRETE AND THEIR $\mathrm{CO}_{2}$ EMISSIONS (2019)

\begin{tabular}{|c|c|c|c|c|c|}
\hline Fossil fuel & $\begin{array}{c}\text { Annual } \\
\text { consumption } \\
\text { (tn) }\end{array}$ & $\begin{array}{l}\text { Energy } \\
\text { content } \\
(\mathrm{MWh})\end{array}$ & $\%$ & $\begin{array}{c}\text { Annual } \mathrm{CO}_{2} \\
\text { emissions } \\
\text { (tn) }\end{array}$ & $\%$ \\
\hline Diesel oil $^{1}$ & 40,294 & 491,886 & 49.73 & 131,334 & 62.36 \\
\hline Fuel oil $^{1}$ & 6,683 & 81,553 & 8.24 & 22,748 & 10.80 \\
\hline $\mathrm{LPG}^{1}$ & 17,705 & 235,473 & 23.81 & 56,513 & 26.84 \\
\hline $\begin{array}{l}\text { Total-fossil } \\
\text { fuels }\end{array}$ & 64,682 & 808,912 & 81.78 & 210,595 & 100 \\
\hline $\begin{array}{l}\text { Total-fossil } \\
\text { fuels per } \\
\text { capita }^{1}\end{array}$ & & 1.274 & & 0.332 & \\
\hline $\begin{array}{c}\text { Biomass }^{2} \\
\text { Solar }\end{array}$ & & 60,000 & 6.06 & 0 & 0 \\
\hline $\begin{array}{l}\text { thermal } \\
\text { energy }^{2}\end{array}$ & & 120,178 & 12.16 & 0 & 0 \\
\hline $\begin{array}{c}\text { Total } \\
2\end{array}$ & & 180,178 & 18.22 & 0 & 0 \\
\hline $\begin{array}{l}\text { Total - REs } \\
\text { per capita }^{2}\end{array}$ & & 0.284 & & 0 & \\
\hline Total & & 989,090 & 100 & 210,595 & 100 \\
\hline $\begin{array}{c}\text { Total per } \\
\text { capita }\end{array}$ & & 1.558 & & 0.332 & \\
\hline
\end{tabular}

Source: ${ }^{1}$ www.statistics.gr, ${ }^{2}$ Draft plans for clean energy transition in the island of Crete, Greece, 2020, Inhabitants in Crete $=634,930$.
Heat and cooling are also generated in Crete with electric devices. Electricity is mainly generated in the island by fossil fuels while part of it by REs. The island's electric grid is autonomous while it is currently in the stage of interconnection with the grid of continental Greece with two undersea electric cables. This will soon allow the interchange of electricity between Crete and continental Greece. It is expected that many new solar-PV systems and wind farms, which are highly profitable, will be installed in Crete generating large amounts of green electricity reducing the island's dependence on fossil fuels. Future electrification of the heating and cooling sector in Crete will be based in green, renewable, carbon-free electricity. The fossil fuels currently used for heat production in Crete can be gradually replaced with:

a) Local biomass resources for heat production,

b) Solar energy with thermosiphonic solar thermal systems with flat plate solar collectors for heat production,

c) Solar thermal cooling systems with sorption chillers for cooling generation, and

d) Electricity derived by renewable energies for heat and cooling generation with heat pumps, airconditioning systems, electric heaters, and electric boilers.

Heat and cooling generation, excluding the use of electric systems, has a small impact in the final energy consumption and carbon emissions in Crete as indicated in Table IV. Heat and cooling generation, excluding the use of electric systems, has a share at $5.62 \%$ in the final energy mix while their share in carbon emissions is even lower at $1.65 \%$.

TABLE IV: FINAL ENERGY CONSUMPTION AND $\mathrm{CO}_{2}$ EMISSIONS IN CRETE (2018 AND 2019)

\begin{tabular}{|c|c|c|c|c|}
\hline Energy sector & $\begin{array}{l}\text { Annual energy } \\
\text { consumption } \\
\text { (MWh) }\end{array}$ & $\%$ & $\begin{array}{c}\text { Annual } \mathrm{CO}_{2} \\
\text { emissions (tn) }\end{array}$ & $\%$ \\
\hline $\begin{array}{c}\text { Electricity } \\
\text { generation (2019) }\end{array}$ & $3,071,926$ & 20.48 & $6,954,999$ & 67.55 \\
\hline $\begin{array}{l}\text { Transportation in } \\
\text { the island (2018) }\end{array}$ & $3,987,906$ & 26.58 & $1,126,268$ & 10.94 \\
\hline $\begin{array}{l}\text { Transportation to } \\
\text { and from Crete } \\
\text { (estimations) }\end{array}$ & $7,099,450$ & 47.32 & $2,045,044$ & 19.86 \\
\hline $\begin{array}{l}\text { Heat and cooling } \\
\text { excluding electric } \\
\text { systems }(2018)\end{array}$ & 843,648 & 5.62 & 170,008 & 1.65 \\
\hline Total & $15,002,930$ & 100 & $10,296,320$ & 100 \\
\hline
\end{tabular}

\section{USE OF RENEWABLE ENERGY SOURCES FOR HEAT AND COOLING GENERATION IN CRETE}

Various renewable energies are currently used for heat and cooling generation in Crete comprising solar energy, biomass, and ambient heat. Geothermal fields with water temperatures above $50-70{ }^{\circ} \mathrm{C}$ have not been found so far in Crete.

\section{A. Use of Solar Energy for Heat Production}

Solar energy is broadly used with solar thermal systems for DHW production in temperatures at around $50-70{ }^{\circ} \mathrm{C}$ in Crete. The high solar irradiance in the island favors the use of solar energy, particularly in summer, for DHW 
production. Summer operating hotels can cover a significant amount of requirements in DHW with solar energy. Residential buildings also can cover the most of their annual needs in DHW with solar energy. Mostly thermosiphonic systems with flat plate solar collectors are used in residential and commercial buildings including hotels. Solar heating systems are also used in agriculture and in industry. The solar thermal technology for DHW production is mature, reliable, well proven, and cost-efficient. Greece is a European country with high penetration of solar thermal systems. However further deployment of this technology is possible and desirable in Crete. The government is currently supporting the technology through the EU structural funds. Capital subsidies are offered for the installation of these systems in private and public buildings, in hotels and in industry.

\section{B. Use of Solar Thermal Energy for Cooling Production}

The climate in Crete is mild Mediterranean type and buildings require more cooling than heating compared to northern EU countries. Solar energy resources are also abundant in the island. Solar energy can be used for space cooling with solar thermal cooling systems and sorption chillers. Space cooling in buildings is needed in Crete when the solar irradiance is high. Solar thermal cooling systems have lower efficiencies compared to conventional airconditioning systems using heat pumps. Their COP is below 1 , when the driving temperature is at around $70-75{ }^{\circ} \mathrm{C}$, compared with COPs higher than 3 to 4 achieved in modern heat pumps. It has been reported that they are cost competitive only when they are used in double-stage systems achieving higher COPs than single-stage units. Their use is more attractive in large installations like in large summer operating hotel resorts or in hospitals. While the use of solar thermal cooling systems is increasing in Europe and worldwide their use in Crete is rather limited. Although the technology is desirable its reliability and cost-efficiency should be improved for increasing its use in the island. The Greek government is currently subsidizing the installation cost, through EU structural funds, promoting the deployment of solar thermal cooling systems.

\section{Use of Biomass for Heat Production}

Local biomass resources are broadly used in Crete for heat production in buildings, greenhouses and in industry. Due to the extensive olive tree cultivation in the island, there are large quantities of olive tree wood, olive tree pruning and olive kernel wood which consist of an excellent renewable fuel for heat production. Olive kernel wood that is a by-product of the olive oil producing industry is extensively used for space heating, hot water, and steam production. Its burning characteristics are very good while its price is low compared with its heating content. Olive kernel wood is currently processed, refined, and standardized locally while it is used for space heating like wood pellets. The technology of burning local biomass resources for heat generation in Crete is mature, reliable, well proven, and cost-efficient. Like solar thermal energy the government is supporting, with EU structural funds, the use of local biomass in buildings subsidizing the installation cost of the heating systems. Solid biomass is burnt in various systems including wood fires, wood stoves and central heating systems. Biogas produced in Crete via anaerobic digestion of organic wastes is used for cogeneration of heat and power. Additionally, to olive tree biomass citrus tree's wood is also used for heat generation in the island.

\section{Use of Ambient Heat for Heat and Cooling Generation}

Low enthalpy geothermal energy can be used with high efficiency heat pumps for heating and cooling. Heat pumps have high efficiencies in the range 3-4 or even higher. Due to high COPs their use in buildings, in agriculture and in industry is increasing worldwide. Heat pumps utilize electricity combined with the ambient heat generating more heat and cooling than the electricity consumed. In the current era of climate change their high efficiency and the low carbon emissions during their operation favors their use. When the heat pumps are powered with renewable electricity derived in Crete from solar-PVs and wind farms the generation of heat and cooling is carbon free. Operation of heat pumps does not create local pollution problems, like solid biomass burning, and their use in residential or commercial buildings is increasing. The capital cost of heat pumps is high compared to electric heaters but due to their high operating efficiency they are cost-competitive in the long run. Their use in buildings improves their energy performance and their rating. The Greek government offers financial subsidies, through the EU structural funds, supporting their installation cost and increasing their attractiveness in heat and cooling generation.

\section{USE OF ELECTRICITY FOR HEAT AND COOLING GENERATION IN CRETE}

Electricity is currently used for heat and cooling generation in Crete with various systems. Electric heaters are used in space heating while electric boilers in DHW production. Heat pumps are used for heat and cooling generation as well as for DHW production. Various other air-conditioning systems are used for space cooling.

\section{A. Electric Heaters and Boilers}

Electricity is used for space heating with electric heaters and for DHW production with electric boilers which can be also used for heat storage. The cost of electric heaters is relatively low compared with the cost of heat pumps, but their efficiency is also lower. Electric boilers are used either as the main energy system producing DHW in buildings or complementing the solar thermosiphonic systems during periods of low solar radiation while their capital cost is rather low. When the electricity used in these heat producing systems is generated by REs the heat generation can be considered as carbon free.

\section{B. Air-conditioning Systems and Heat Pumps}

Cooling can be produced either with air-conditioning systems or with heat pumps. Both are powered by electricity. The cooling production is based on compression and evaporation of a refrigerant. Apart from space cooling heat pumps can also generate heat and DHW efficiently while their capital cost is higher. Air-conditioners can generate cooling but if heat is required during the winter 
season an additional heating system will be needed. The renewable energy technologies and the electric systems that are used for heat and cooling generation in Crete are presented in Table V.

TABLE V: RENEWABLE ENERGY TECHNOLOGIES AND ELECTRIC SYSTEMS CURRENTLY USED FOR HEAT AND COOLING GENERATION IN CRETE

\begin{tabular}{|c|c|c|c|}
\hline Energy source & Technology & $\begin{array}{c}\text { Generated } \\
\text { energy }\end{array}$ & Application \\
\hline $\begin{array}{l}\text { Solar thermal } \\
\text { energy }\end{array}$ & $\begin{array}{l}\text { Thermosiphonic } \\
\text { systems with flat } \\
\text { plate collectors }\end{array}$ & DHW & Broad use \\
\hline $\begin{array}{l}\text { Solar thermal } \\
\text { energy }\end{array}$ & $\begin{array}{l}\text { Solar thermal } \\
\text { sorption systems }\end{array}$ & Cooling & $\begin{array}{l}\text { Only two old } \\
\text { systems exist }\end{array}$ \\
\hline Biomass & Burning & Heat, DHW & Broad use \\
\hline $\begin{array}{l}\text { Ambient heat } \\
\text { combined } \\
\text { with } \\
\text { electricity }\end{array}$ & Heat pumps & $\begin{array}{l}\text { Heat, } \\
\text { cooling, } \\
\text { DHW }\end{array}$ & Broad use \\
\hline Electricity & Electric heaters & Heat & Broad use \\
\hline Electricity & Electric boilers & DHW & Broad use \\
\hline Electricity & $\begin{array}{l}\text { Air-conditioning } \\
\text { systems }\end{array}$ & Cooling & Broad use \\
\hline
\end{tabular}

Source: Own estimations.

\section{OTHER SUSTAINABLE ENERGY TECHNOLOGIES GENERATING HEAT AND COOLING}

Other low or zero carbon emission technologies including CHP systems, district heating systems and district cooling systems are not currently used in Crete.

\section{A. Co-generation Systems}

CHP systems can be used for heat and power cogeneration in Crete with low carbon impacts although their use is not propagated so far. They can be fueled by LPG since natural gas is not available in the island. Co-generated electricity can be injected into the grid according to the current regulations. Ideal users of CHP systems are large heat and power consumers in Crete like hospitals or large hotel complexes. The government currently promotes the installation of CHP systems with attractive financial subsidies.

\section{B. District Heating and Cooling}

District heating and cooling systems offer heat and cooling at an affordable cost while they have many environmental benefits. The climate in Crete is mild and the annual heating needs are low compared to northern EU countries. However, the requirements for cooling are high. Therefore, the use of district cooling systems instead of district heating systems seems more attractive. District heating and cooling systems have not been installed so far in the island.

\section{CARBon EMISSIONS DUE TO DIRECT USE OF FosSIL FUELS IN THE HEATING SECTOR IN CRETE}

The carbon emissions due to fossil fuels use in the heating sector in Crete have been evaluated at 210,595 $\mathrm{tnCO}_{2} /$ year (Table II). The most of them, at $62.36 \%$, are related with the use of diesel oil. It is assumed that the use of solar energy and biomass for heat and DHW production has carbon neutral impacts. Apart from fossil fuels use heat and cooling is also generated with electric heaters, electric boilers, heat pumps and air-conditioning units powered with electricity. It is estimated that currently around $78 \%$ of the electricity in Crete is generated by fossil fuels while the rest by REs. Neglecting the indirect contribution of fossil fuels in heat and cooling generation, using various electric devices, the annual carbon emissions per capita in the island due to direct use of fossil fuels, in the heating and cooling sector, are estimated at $0.33 \mathrm{tnCO}_{2} /$ capita taking into account that the current population in Crete is 634,930 inhabitants. These carbon emissions can be compared with the total carbon emissions in Greece in 2016 at $5.79 \mathrm{tnCO}_{2} /$ capita [32].

\section{ThE DE-CARBOnIZATION OF THE HEATING AND COOLING SECTOR IN CRETE}

Heat and cooling generation in Crete is currently based on electricity, fossil fuels and renewable energies. The interconnection of the island's electric grid with the Greek continental grid with two undersea transmission cables is going to be finalized in the next 2-3 years. After the interconnection of the grids, it is expected that in the medium and long term the electricity generation in Crete will be fully de-carbonized mainly using the abundant local solar and wind energy resources combined with electricity storage systems like water pump storage systems and electric batteries. De-carbonization of the heating and cooling sector in Crete can be obtained with replacement of the currently used fossil fuels with renewable energies and renewable electricity provided that electricity generation will be fully de-carbonized in the island. The required technologies, presented in table 4 , are mature, reliable, well proven and cost efficient. Technological improvements could allow the future use of additional benign energy technologies, like solar thermal cooling, in Crete.

\section{DISCUSSION}

Due to mild climate in the island carbon emissions due to heat and cooling generation are lower compared with the corresponding emissions in electricity generation and in transportation. Our results indicate that heat and cooling in the island is currently produced by fossil fuels, renewable energies and electricity using different energy technologies. Our estimations regarding carbon emissions due to direct use of fossil fuels for heat and cooling generation in Crete are approximately $20 \%$ higher than the corresponding estimations reported in previous studies. The Greek government offers financial subsidies through the EU structural funds to sustainable energy investments in private and public buildings improving their energy performance. During the economic crisis, in the previous ten years, fossil fuels use in heat and cooling generation in Crete has been significantly decreased at around one third of the pre-crisis consumption levels. Heating oil, fuel oil and LPG use in Crete can be replaced with renewable energies and electricity. Due to current interconnection of the electric grids of Crete and continental Greece electricity in Crete is foreseen to be generated in the future with solar and wind energy. Therefore, it is indicated that de-carbonization of the heating and cooling sector in the island is feasible using 
renewable energies and electric systems powered by renewable electricity eliminating the consumption of fossil fuels. However, our results do not estimate the amount of heat and cooling generated by renewable energies as well as by electric systems using renewable electricity. Our results are useful for the development of the island's clean energy transition plan. Although energy transition requires the active participation of all stakeholders our results confirm the technical feasibility of de-carbonizing the heating and cooling sector in the island.

\section{CONCLusions}

The de-carbonization of the heating and cooling sector in the island of Crete, Greece has been studied. Fossil fuels, renewable energies and electricity are currently used for heat and cooling generation. The main renewable energies used are solid biomass, solar energy, and ambient heat with heat pumps. The fossil fuels used are heating oil, fuel oil and LPG. The energy content of fossil fuels has been estimated at $808,912 \mathrm{MWh} /$ year or $1.27 \mathrm{MWh} /$ capita-year while their carbon emissions at 210,595 tnsCO $\mathrm{CO}_{2} /$ year or at $0.33 \mathrm{tnsCO}_{2} /$ capita-year. The energy content of REs has been estimated at $180,178 \mathrm{tnsCO}_{2} /$ year or $0.28 \mathrm{MWh} /$ capitayear while their carbon emissions are zero. The energy content of the fossil fuels used in heating and cooling in Crete is around 4.5 times higher than the energy content of the solar energy and biomass used. After the global economic crisis at 2007-2008 a significant amount of diesel oil used in heat production in Crete has been replaced by electricity and REs. Elimination of fossil fuels use in heating and cooling in the island is feasible using REs including solar energy and biomass and various electric devices powered by renewable electricity. The required technologies are mature, reliable, and cost efficient. The interconnection of the electric grids of Crete and continental Greece is going to be finalized in the next two to three years and after that is expected that electricity will be generated in the island using solar and wind energy minimizing, or even eliminating, the use of fossil fuels. The abundant solar and wind energy resources in Crete allow the generation of low-cost electricity with solar-PV systems and wind farms. Our results indicate that de-carbonization of the heating and cooling sector in Crete is technically feasible provided that after the interconnection of the electric grids electricity generation in Crete will be also de-carbonized. The findings could be useful to policy makers designing the appropriate policies aiming to achieve the target of carbon neutral Crete complying with the EU goal for carbon neutral Europe by 2050. Future research should be focused on the decarbonization of the electricity generation and the transportation sectors in the island.

\section{REFERENCES}

[1] R. Sinha, B. Ban-Jensen, J. Radhakrishna Pillai, and H. Zareipour, "Flexibility from electric boilers and thermal storage for multi energy system interaction", Energies, vol. 13, pp. 98, 2020. doi:10.3390/en13010098.

[2] F. Schipfer, L. Kranzl, O. Olsson, and P. Lamers, "European residential wood pellet trade and prices dataset", Data in Brief, vol. 32, 106254, 2020. https://doi.org/10.1016/j.dib.2020.106254.
[3] E. Kyriaki, E. Giama, A. Papadopoulou, V. Drosou, and A.M. Papadopoulos, "Energy and Environmental performance of solar thermal systems in hotel buildings", Procedia Environmental Sciences, vol. 38, pp. 36-43, 2017. doi: 10.1016/j.proenv.2017.03.072.

[4] Ch. Malamatenios, "Greek solar thermal market", presented at the GSS-VET workshop, Athens, February $13^{\text {th }}, 2020$.

[5] District heating in buildings, Euroheat and Power, 2011. Available at http://www.buildup.eu/sites/default/files/content/District\%20Heating $\% 20$ in\%20buildings_final.pdf [21/5/2021].

[6] E. Negro, N. Cardinale, and G. Rospi, "Design of small cogeneration system for public buildings in the town of Matera", International Journal of Heat and Technology, vol. 35(1), pp. 228-235, 2017. doi:10.18280/ijht.35Sp0132.

[7] H. Valdes and G. Leon, "Cogeneration process technical viability for an apartment building: Case study in Mexico", Processes, vol. 7, 93, 2019. doi: $10.3390 /$ pr7020093.

[8] M. Karagiorgas, "Solar thermal systems in EU and Greece", presented at the CEE solar 2008, Shedding light on the emerging solar market, 21 November 2008. Available at http://www.cres.gr/transsolar/downloads/Event_Romania/06.pdf [21/5/2021].

[9] Th. Tsoutsos, J. Anagnostou, C. Pritchard, M. Karagiorgas, and D. Agoris, "Solar cooling technologies in Greece. An economic viability analysis", Applied Thermal Engineering, vol. 23, pp. 1427-1439, 2003. doi:10.1016/S1359-4311(03)00089-9.

[10] Solar heating and cooling \& solar air-conditioning, Task 53, New generation solar cooling \& heating systems (PV or solar thermally driven systems), IEA, 2018. Available at http://task53.ieashc.org/Data/Sites/1/publications/IEA-SHC-Solar-Heating-andCooling-Solar-AC-Position-Paper-summary.pdf [21/5/2021].

[11] T.C. Roumpedakis, S. Vasta, A. Sapienza, G. Kallis, S. Karellas, U. Wittstadt, M. Tanne, N. Harborth, and U. Sonnenfeld, "Performance results of a solar absorption cooling and heating unit", Energies, vol. 13, 1630, 2020. doi:10.3390/en13071630.

[12] Solar heating and cooling for residential applications, Technology brief R12, IEA and IRENA, 2015. Available at https://www.irena.org/-

/media/Files/IRENA/Agency/Publication/2015/IRENA_ETSAP_Tech _Brief_R12_Solar_Thermal_Residential_2015.pdf [21/5/2021].

[13] S. Alatzas, K. Moustakas, D. Malamis, and S. Vakakis, "Biomass potential from agricultural waste for energetic utilization in Greece", Energies, vol. 19, 1095, 2019. doi:10.3390/en12061095.

[14] O. Christodoulou, M. Fountoukidou, St. Sakellariou, St. Tampekis, F Samara, A. Sfoungaris, A. Stergiadou, G. Tsantopoulos, K. Soutsas, and I. Sfoungaris, "Energy autonomy in small islands in the frame of their sustainable development exploring biomass energy potential in Samothrace (Greece)", International Journal of Sustainable and Green Energy, vol. 6(4-1), pp. 9-17, 2015. doi: 10.11648/j.ijrse.2015060401.12.

[15] J.W. Lund, and T.L. Boyd, "Direct utilization of geothermal energy, 2015 Worldwide Review", Presented at the proceedings of World Geothermal Congress 2015, Melbourne, Australia, 19-25 April 2015.

[16] K.M. Bataineh, and S. Alrifai, "Recent trends in solar thermal sorption cooling system technology", Advances in Mechanical Engineering, vol. 7(5), pp. 1-20, 2015. doi: $10.1177 / 1687814015586120$.

[17] V. Aggarwal, Ch. Swaroop Meena, A. Kumar, T. Alam, A. Kumar, A Chosh, and A. Chosh, "Potential and future prospects of geothermal energy in space conditioning of buildings: India and Worldwide Review", Sustainability, vol. 12, 8428, 2020 doi:10.3390/su12208428.

[18] I. Diaz de Cerio Mendaza, B. Bak-Jensen, and Z. Chen, "Electric boiler and heat pump thermo-electrical models for demand size management analysis in low voltage grids", International Journal of Smart Grid and Clean Energy, vol. 2(1), pp. 52-59, 2013.

[19] Renewable heat sources: The best available solution to de-carbonize the heating sector, Joint position paper, May 2017. Available at http://www.estif.org/fileadmin/estif/Electrification-HC_AEBIOMEGEC-ESTIF_April-2017-1.pdf [21/5/2021].

[20] Renewable power to heat, Innovation Landscape Brief, International Renewable Energy Agency, 2019. Available at https://www.irena.org/-

/media/Files/IRENA/Agency/Publication/2019/Sep/IRENA_Powertoheat_2019.pdf?la=en\&hash=524C1BFD59EC03FD44508F8D7CFB8 4CEC317A299 [21/5/2021].

[21] Heat from renewable energy sources, The RES-initiative and related directives, 2002 Available at https://ec.europa.eu/clima/sites/default/files/eccp/second/docs/renewa ble_energy_srcs_heat_en.pdf. 
[22] Draft plan for energy transition in the island of Crete, Greece, 2020. Personal communication with Dr. N. Zografakis, Region of Crete.

[23] Islands transition handbook - How to develop your island's clean energy transition agenda, 2020. Available https://www.euislands.eu/sites/default/files/201910/eu_islands_transition\%20handbook_IA_web.pdf [21/5/2021].

[24] EU islands in the energy transition, A catalogue of good practices, 2019. Available at: https://euislands.eu/sites/default/files/eu_islands_good_practice_IA.p df.

[25] F. Polzin, and M. Sanders, "How to finance the transition to lowcarbon energy in Europe", Energy Policy, vol. 147, 111863, 2020. https://doi.org/10.1016/j.enpol.2020.111863.

[26] D. Loorbach, and J. Rotmans, "The practice of transition management: Examples and lessons from four distinct cases", Futures, 2010. doi:10.1016/j.futures.2009.11.009.

[27] J. Vourdoubas, "Present and future uses of biomass for energy generation in the island of Crete, Greece", Journal of Energy and Power Sources, vol. 2(4), pp. 158-163, 2015.

[28] www.statistics.gr.

[29] H.M. Marczinkowski, P.A. Ostergaard, and S.R. Djorup, "Transitioning island energy systems - Local conditions, development phases, and renewable energy integration", Energies, vol. 12, 3484, 2019. doi:10.3390/en12183484.

[30] H. Dorotic, B. Doracic, V. Dobravec, P. Tomislav, and G. Krajacic, "Integration of transport and energy sectors in island communities with $100 \%$ intermittent renewable energy sources", Renewable and Sustainable Energy Reviews, vol. 99, pp. 109-124, 2019 https://doi.org/10.1016/j.rser.2018.09.033.

[31] J. Vourdoubas, "Use of renewable energy sources for energy generation in rural areas in the island of Crete, Greece", European Journal of Environment and Earth Sciences, vol. 1(6), pp. 1-7, 2020. Doi:10.24018/ejgeo.2020.1.6.88.

[32] http://data.worldbank.org. 